\title{
Advances in Chemistry and Their Implications for Studying and Treating Brain Disease*
}

\author{
Robert Langer ${ }^{1}$
}

Chemical approaches to creating new drug delivery systems and biomaterials are discussed. These delivery systems have been used to study how blood vessels grow and how different molecules affecting the brain behave. They have also been used in treatments ranging from schizophrenia to brain cancer.

Keywords: Polymer; Biomaterial; Drug Delivery.

Thank you so much. For a start I should say that I am not a neuroscientist though I did marry one. I am actually a chemical engineer. However, Bengt asked me to speak at this fantastic symposium. I'm honored to do so and I am going to try and explain how chemical engineering, in a couple of ways, could relate to neuroscience. As I was preparing this talk, what I thought l'd do as there are many high school students here, is try to put myself back in your place and think about what might be useful.

I thought I would tell you just a little bit about my own career and how I got to be here today. When I went to college, I majored in chemical engineering and when I was done there was this gas shortage in the United States, and what happened is the prices of gas at all these gas stations kept going up and up and up. But the thing is, if you were a chemical engineer, you got a lot of job offers. I remember pretty much everyone of my classmates went to work in the oil industry. So, I thought I should do the same. I actually got 20 job offers, four from Exxon alone. And it wasn't like I was that good. But they had a lot of job openings. However, when I went to these interviews, I wasn't very excited about what I heard. What they are talking about was increasing the yield of oil or some of these petrochemicals by about $0.1 \%$ and I really wanted to make more of an impact. I wanted to do something that I felt would really help people.

One of the things I did when I was in college was to start a school for poor children in Cambridge which is where MIT is located. And one of the main things that I did was to develop new chemistry curricula to try to make chemistry more interesting. I loved that. One day I saw an ad to be an assistant professor at an American college to develop chemistry curricula and I wrote them a letter applying for the job. But they didn't write me back. But I really liked the idea. So I found all the ads I could where you could do something like that. I wrote to about 40 colleges to apply for being assistant professor to do that. None of them wrote me back.

I guess even if you went to MIT and you weren't in the chemistry education box, you don't get a letter back. So I started to think about what other ways I could use my education to help people. I thought about medicine. So I wrote to a lot of hospitals and medical schools. They didn't write me back either. But then one day, one of the people in the lab where I was said to me "Bob, there is a surgeon in Boston named Judah Folkman and sometimes he hires unusual

\footnotetext{
${ }^{1}$ David H. Koch Institute Professor, Massachusetts Institute of Technology. Published online 16 May 2017; doi:10.1142/S2529732517400016 *This article was transcribed from a presentation delivered by Professor Langer at the Molecular Frontiers Symposium in Stockholm in 2014. It is published here in MFJ with permission from Professor Langer.

This is an Open Access article published by World Scientific Publishing Company. It is distributed under the terms of the Creative Commons Attribution 4.0 (CC-BY) License. Further distribution of this work is permitted, provided the original work is properly cited.
} 


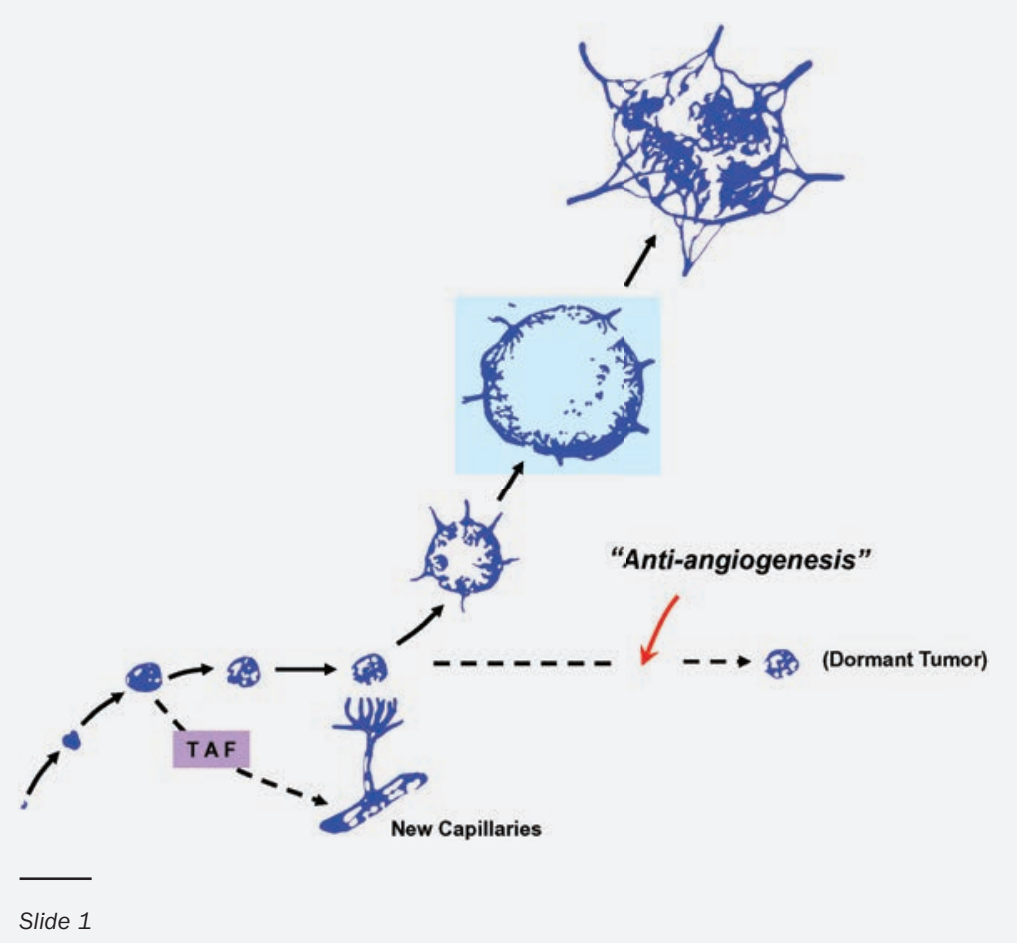

we had in the lab, but I couldn't get very much. One of the things you learn in chemical engineering is scale up. So I went to cows and I got some cow bones at a slaughterhouse but I couldn't get that many bones. So I asked where do all the bones go and I found out they went to all these meat packing places in Boston. I made arrangements with them to get all the bones and bring them to the lab.

Here's a picture of one of them (Slide 2). Normally there is a good bit of meat on it, but I had scrapped it off and I did this for thousands of bones. Then I sliced the cartilage off and worked out ways to extract it with different solvents like guanidine hydrochloride. Then I purified it into different fractions. At the end of a couple of years, I had hundreds of different fractions I wanted to test. That brings up the second problem. How do you test whether a substance could stop blood vessels from growing?

people." He thought very, very highly of Dr. Folkman. I won't say what he thought about me.

This is actually a picture of Dr. Folkman's idea about how tumors grow (Slide 1) and what he said was tumor cells become abnormal and they grow to about a millimeter cubed but then they run into a nutrition problem. Cells in the center can't get nutrients or get rid of wastes. So they die. However, Dr. Folkman thought that somehow the tumor secretes a signal called TAF (Tumor Angiogenesis Factor). Normally blood vessels just hang around and don't do much but he thought that in the presence of TAF these vessels start to multiply and grow right to the tumor. That solves the tumor nutrition problem because it gives the tumor a blood supply. That causes the second phase of growth and when this happens, the tumor gets bigger and bigger and also it can spread through these blood vessels. That process is called metastasis and eventually it can kill. By the way, brain tumors are among the most vascularized tumors in the body.

One of the things he said was if you could stop angiogenesis, maybe that will be a whole new way of stopping cancer. So when I came to his lab he asked me to prove this theory and actually isolate, for the first time, a substance that could stop blood vessels from growing. So how do you think about a problem like that? How do you think about finding a new factor? We broke up the problem into two parts. The first part is where could you even find something that might stop blood vessels from growing. One of the things we thought about is cartilage. I started to get cartilage from little rabbits
If you look back at the history of medicine and biology, one of the things you see when people try to come up with different factors is really what's often rate limiting is a bioassay. In this case, there was none. And it was not easy to do because there is always background blood vessels in the body or an organism you might study. So we were trying to

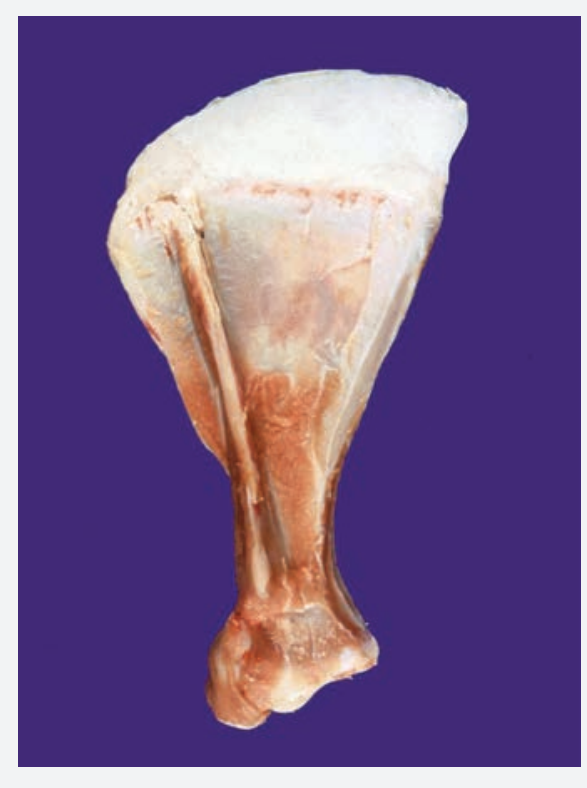

Slide 2 
think how could we create a bioassay. One of the things we thought about was the eye of a rabbit. We chose it for a couple of reasons. First, it's actually fairly easy to see, and rabbits have big eyes. You can look at them through an ophthalmic microscope, but also what we found is that certain types of tumors will cause blood vessels to grow from the edge of the cornea to the tumor over about a two- or three-month period. There's no background blood vessels in the cornea and you could follow how fast vessels grow in the presence of different substances. But what we needed, since the molecules in cartilage were fairly large molecules like proteins, is a little polymer pellet that we could put right next to the tumor that would slowly emit any of the factors that we isolated.

So that was actually a key problem. Could we come up with a polymer pellet that would not cause harm to the eye and that could release molecules of any size? That was very challenging. That had never been done and actually Dr. Folkman (this was 1974) was on the advisory board of the one company (ALZA) in the world working on materials that could release drugs. At that point one could only slowly release a couple of small molecules. Everyone told him that you can't slowly release large molecules. In fact, a Nobel Prize winner on the board with Dr. Folkman, said that it is impossible for large molecules to get through the polymers. He said it's like walking through a solid wall. Alternatively, you could make it very porous. But then the molecules would go through the wall instantaneously. So the challenge was could we come up with a way to deliver molecules of any size over a long period of time. In fact, the literature said pretty much the same thing - that it couldn't be done.

I spent two or three years in the laboratory experimenting with different techniques and I found over 200 different
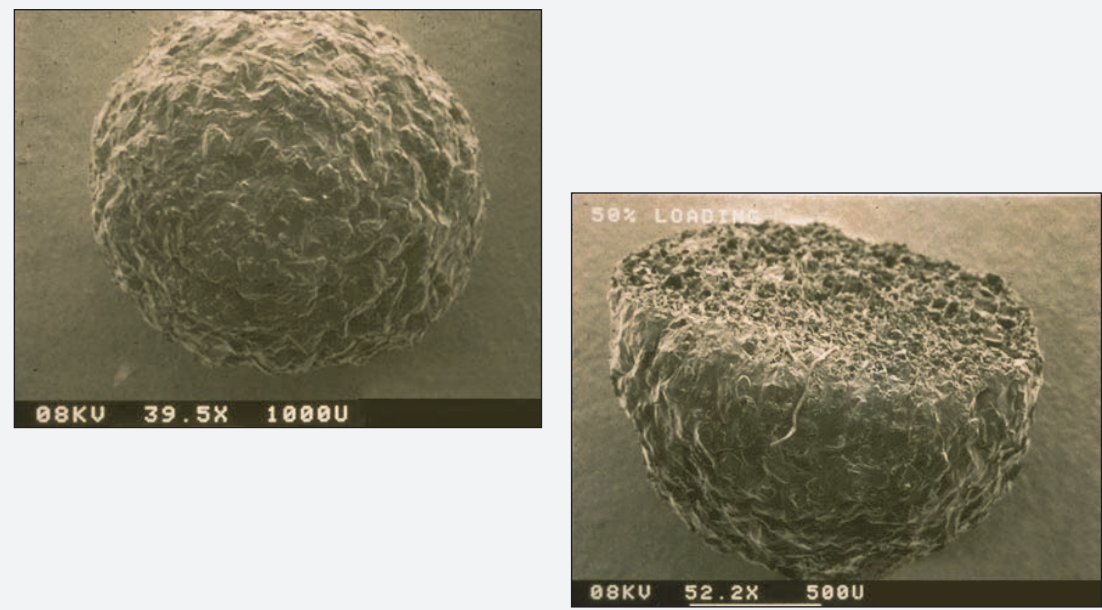

Slide 3 ways to get this to not work. But eventually I was able to make little microspheres. Here's a picture of one and one cut in half (Slide 3). In fact, now we also make nanospheres as well. We published a paper in Nature in 1976 showing for the first time you could release molecules of virtually any size for over a hundred days and get activity. Later on we worked out ways to even get constant release.

In 1976, I got asked for the first time in my life to give a presentation at a scientific meeting and it was to a group of older, very distinguished chemists and chemical engineers. The only talk I had ever given before that was in $8^{\text {th }}$ grade and that talk didn't go real well. I remember in $8^{\text {th }}$ grade what happened is I had to give this minute and a half speech so what I did was I wrote it out and the night before I stood in front of my parents' mirror for three hours just reciting it over and over again. But the next day I got up in front of my $8^{\text {th }}$ grade class and I started to recite the speech. For the first minute and two seconds I did okay, but then I could not remember the next word. So I stood up in front of my $8^{\text {th }}$ grade class for another minute just absolutely frozen and said nothing until my $8^{\text {th }}$ grade teacher finally told me to sit down and gave me not a particularly good grade. I think it was an F. So now, as I said, many years later I had to give this talk in 1976 to this very distinguished group of polymer chemists and engineers. I practiced for a couple of weeks and when I was done with this 20-minute talk, I thought I did much better. I didn't forget too much of what I was going to say. I didn't stammer too much. So I thought when I was done with this talk that these older chemists and engineers, being nice people, would encourage me, this young guy. But when I stepped off the podium, a whole bunch of them came up to me and they said "We don't believe anything you just said."

They said, just like the ALZA people, that the large molecules can't diffuse through solid polymers. Also, we used organic solvents and they said that's going to destroy a lot of the substances you put in. Actually things got worse after that. I remember the first nine grants that I wrote to the government to try to fund this work got turned down and even at MIT when I became a professor there, after the first year or two, the Department Head who hired me, Nevin Scrimshaw, left and so they had different associate department heads and they both decided to sit down with me at 
different times and gave me advice. Their advice was to look for another job.

But one key thing in science is people ultimately repeating what you do. What happened is, by 1979 , different research groups started using what we did and then the question shifted to but how could this possibly work? And to understand that what we did is cut thin sections through these polymers with a microtome. If we took five micron thin sections, it turns out that molecules of 200 molecular weight or greater can't go from one side to the other. But if you put a drug in the polymers, then you see a phase separation. However, if you release it for a year and then you cut a thin section what you see in sharp contrast to what we saw before are pores. These pores didn't exist when there was no drug. So they're made by the way we processed the polymer. These pores are large enough so that molecules even millions of molecular weight can get through. But what happens is if you do serial sectioning and image analysis, you see tight constrictions between the pores and the pores are incredibly winding and tortuous so it takes a really long time for the molecules to wind their way through. Over the years, our students have worked out ways to regulate that tortuosity by various means, e.g., changing the particle size of the drugs, changing the amount of the drug, coating the system or changing the molecular weight of the polymers. We have learned over the years we can make these systems very slowly release or very quickly release, and our students have created mathematical models whereby you can predict all these things. So having developed this foundation, now we were in a position to address different problems.

\section{Rabbit corneal pocket assay}

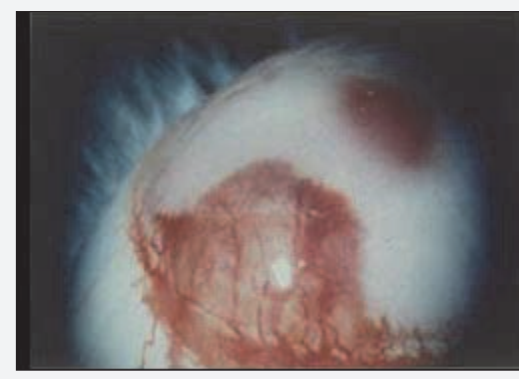

$-C D I$
I'll just give you three different examples of what we tried to do.

First, of course, is why we started this? Angiogenesis. I mentioned the bioassay we wanted to develop and now we did have these polymer pellets. So what I did is now I had all these different factions I want to test. So I actually studied 2000 rabbit eyes. Almost every fraction we tested did not work. But one of them did work so I am going to show you rabbit eyes (Slide 4) and this is about eight weeks after the start of an experiment and this was from the paper we wrote in Science in 1976 which is the isolation of the first angiogenesis inhibitor. So this is a tumor. It's a little bit cloudy. This is the blood vessels. Normally you see the sheet of blood vessels growing over the polymer. If you look at this eye, just two or three weeks later it will be three-dimensional and out of the orbit of the eye. We sacrificed the animals before this happens. But when you put the inhibitor in, the vessels are sparser, they avoid the polymer pellet and about 60 per cent of the time these tumors never grow. So we published this in 1976. It took another 28 years from this paper before the first angiogenesis inhibitor was approved by FDA. But starting in 2004 companies like Genentech and others got FDA approval for many angiogenesis inhibitors. Examples include Avastin which is probably the number one or two largest selling biotech drug in history and Lucentis and Eylea which can treat macular degeneration.

The second thing that happened when we published these papers is that it turned out that a lot of developmental biologists and neuroscientists started using them to deliver different factors to study phenomena in the brain because normally if they put these factors in the body, they'd be destroyed right away. You can't study them. So now they put them in these little polymers pellets and use them to study the biologic effects of different molecules. One group studied a molecule that affected eyespecific segregation. Another released a substance to study a mammalian neural map. In another example, they looked at growth in a rat's visual cortex. Another example is actually particularly important to me. This was actually a study at Yale and where they studied the developing spinal cord; the reason that was important to me is because the author was a woman named Susan Hockfield 
who later became President of MIT. So all these examples are of people using polymer pellets in neuroscience studies.

The third thing I wanted to do was to see if our systems could make products that could help patients. This is critical because when you inject many of these molecules they are destroyed in the body. So we wanted to do a proof of principle showing you could release molecules for long times. So we took insulin and released it in a diabetic rat for over 100 days. We did all this work and one of the things that Dr. Folkman once said to me was "We should file a patent." So we filed the patent and for six years in a row, the patent examiner turned it down. Finally our patent lawyer said to me "Bob you should just give up, you're wasting the hospital a lot of money." But I don't like to give up. I kept thinking how can I convince the examiner. When we first did this work, all these people told us — the chemists, and chemical engineers - that this could never work. So I thought to myself I wonder if anybody ever wrote anything like that down. So you can do a science citation search. You can look back at your 1976 Nature paper and see who wrote about it and so I found various different things that people wrote. I'll just show you one. This is from a paper in 1979 referring back to our 1976 paper and the authors were five leading polymer chemists in the world at that time.

They wrote "Generally the agent to be released is a relatively small molecule at molecular weight not larger than a few hundred. One would not expect that macro molecules, for example proteins, could be released by such a technique because of their extremely small permeation rates through polymers. However, Folkman and Langer have found some surprising results that clearly demonstrate the opposite." So I showed this to the hospital's lawyer, and he said that's terrific. He flew down to Washington to see the patent examiner and the patent examiner said that he would allow this patent, if I could get written affidavits from each of these five authors, that they really wrote that. So I wrote to all of them. Each of them was nice enough to write me back that they really wrote that, and we got his very broad patent, for pretty much any polymer and any molecule. From that, we enabled companies to create all kinds of products that are now being used clinically. The polymer approach we developed was critical because many drugs are large and are destroyed immediately. You can't use the drugs otherwise. Also this approach is critical in mental health diseases. Many people don't take their drugs and patient compliance is terrible. The polymer pellets have been used in treatment for prostate cancer and endometriosis, schizophrenia, diabetes and many other diseases.

So this is one story I want to tell you. The second story I want to tell you has a very different origin. I started to think one day "how do materials find their way into medicine?" Is it by chemists or chemical engineers? When I looked into this, that was never the case. Pretty much every time a material found its way into medicine, is that a medical doctor urgently wanted to solve a medical problem and what he or she did was they went to their house to find something that resembles the organs or tissues they want to fix and then they used it in the body.

So, for example, in the case of the artificial heart, what they ended up picking was a lady's girdle material because it has good flexural properties. But it doesn't work very well medically. Blood contacts the surface of the artificial heart. It forms a clot which goes to the patient's brain and they get a stroke and they die. But again if you think about something that's designed to be a lady's girdle that may not be the optimal blood contacting material. Pretty much every material in medicine today has an origin like this. For example, in the case of breast implants, one material was actually a mattress stuffing. So I started to think that we ought to be able to do better. One of the things you learn in chemical engineering is what I called chemical engineering design. So I thought why can't we ask the question, what do we really want in a biomaterial from an engineering standpoint, chemistry standpoint and biology standpoint? And could we totally change the biomaterials paradigm by using chemistry? To start, I picked an example. When I started the only degradable material that was FDA approved were polyesters like sutures. They dissolved by bulk erosion. They start out firm, get spongy and then they fall apart, which means they could readily dump the drug out. This is okay for some drugs but if you had toxic drugs, like a cancer drug or insulin, that would be bad. So from an engineering standpoint you don't want it to dissolve like that. What you really want is surface erosion. How could you do it? I started to ask different design questions.

The first question is what should cause polymer degradation? Should it be water? Should it be an enzyme? Or something else? And so our thinking was since we are going to design it from scratch, everyone has different enzyme levels but we all have excess water. If you want to make this reproducible, we said let's build into the polymer the ability to be degraded by water.

Next, we said what should the nature of the monomers be? We felt if we wanted surface erosion, they had to be hydrophobic to keep the water out. Then the third question was what should the nature of the bonds be? Because when water gets in, we want the bonds to dissolve quickly enough. So this comes down to organic chemistry. You could look at bond liability from very stable to very unstable and we chose the anhydride bond. Our idea was synthesizing hydrophobic polyanhydrides. Then the last question was what should the building blocks (monomers) of these polymers be? Here I asked Michael Marletta to help me. We picked different monomers that he thought would be safe. And then we created a co-polymer. And when we made it, what was exciting 
was not only that these polymers came close to displaying surface erosion, but by just changing the ratios of these different monomers, we could make them last from weeks to years. So you could simply dial in the ratios of these monomers, and make this last as long as you wanted. One of the things that I mentioned earlier that we wanted to do is to see if we could help people with different diseases and Henry Brem who was a young neurosurgeon at John Hopkins in the 1980's came to see me (he's now Chief of Neurosurgery there), and he wanted to have a better way to treat glioblastoma which is a common form of brain cancer and it's uniformly fatal. The drug that they normally used to treat brain cancer at that time, was BCNU, a very toxic drug. Henry asked me if rather than having the neurosurgeon infuse the drugs through the whole body, as they do normally, we could use what we called local delivery. Could the neurosurgeon operate on the patient, take as much as of the tumor out as possible, and then line the cavity with this polymer drug combination. Normally the drug lasts 12 minutes. But if you put it in the polymers, you can protect it and we can make the polymer last for whatever length of time we want. Then you get high drug concentrations in the brain where you want, and low concentrations in the rest of the body.

One of the things is if you come up a new idea, and you are an academic, you always have to raise money. The way we raise money in the US is to write grants to the federal government and then they have what are called study sections which are professors at other universities who review what we do and tell us whether we should get the money or not. So, that's what I did. But we did terribly. In 1981, when we first proposed it, chemists looked at it and said we'll never be able to synthesize the polymers. But I had a very good graduate student, Howie Rosen. Howie, by the way, later became President of ALZA (a \$12 billion corporation) and was also elected to the National Academy of Engineering which is a very, very high honor in the United States, and he synthesized them. So we sent the grant back and the reviewers said they shouldn't fund it because the polymers have anhydride bonds and they will react with whatever drug you put in. But I had other postdocs - Kam Leong, who is now the James Duke Professor at Duke University (and also elected to the National Academy of Engineering) and Bob Linhardt who is a Constellation Professor of Chemistry at RPI and they showed that this didn't happen. So we sent the grant back again and the reviewers said "it still won't work because the polymers are fragile and will break in the body." But I had another couple of postdocs - Edith Mathiowitz who's a Full Professor at Brown University and a member of the National Academy of Inventors, and Avi Domb, who later became Head of Medicinal Chemistry at Hebrew University and they made polymers that were very strong so that they didn't break at all. The next thing the reviewers said is that new polymers are certainly going to be toxic in the body. So they still shouldn't fund it. But I had another graduate student, Cato Laurencin, who was later Dean of Medicine at the University of Connecticut and elected to the National Academy of Engineering and National Academy of Medicine and he showed that the polymers were safe. And this kept going on and on until 1996 when the FDA approved these polymers for human use. It was the first time in 20 years the FDA approved a new treatment for brain cancer, and the first time they ever approved this idea of local chemotherapy. You can probably tell from the way I am speaking that I am very proud of how all the MIT people did. They won tremendous honors and became heads of major corporations and departments whereas the reviewers didn't do so well.

The clinical data from what's called the Phase Three trials were actually done in Sweden and Finland and published in Neurosurgery a number of years ago. And what it shows is that it prolongs life and relieves suffering. It's actually been approved in over 30 countries it has been used for the last 21 years. And it really created a whole new paradigm for localized controlled release which is now used in drug eluting stents and many other areas.

I also wanted to show you a fictional video on this treatment on the popular TV show "ER."

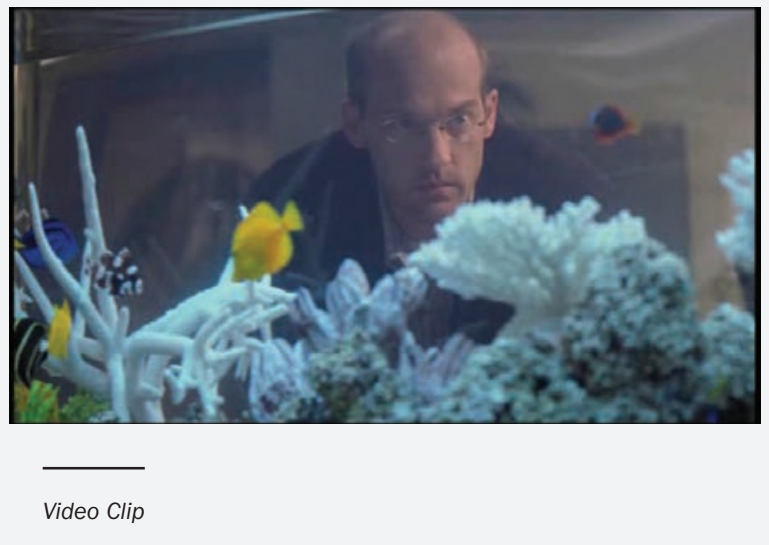

Dr. Burke, nice to meet you

Me too

And you are?

Dr. Elizabeth Cordey, my fiancé

Oh congratulations

Thank you

Sorry to keep you waiting I met some resistance in tumor board

Good or bad? 
The oncologists and radiation therapists are having trouble embracing the future

Meaning?

Come over here. They see a lesion like yours they jump to the conclusion that it's inoperable.

But it is not.

Not in my hands

This is tumor

Now as you were doing verbal tests, there was an increase in blood flow to language centers, those light up in orange.

That's not what the neurosurgeons in Chicago said

That's why you are here.

So you'll operate?

Yeah, we'll do awake craniotomy...consciously talking while I map out brocus and resect the tumor but the real bonus is my ability to insert high dosage chemotherapy wafers into the tumor cavities and use the malignant cells themselves to create a cancer vaccine.

So when can you fit him into the schedule?

About December 31. You can ring in the New Year with a load off your mind.

That's brain surgeon humor

Sure

You okay?

Sure.

It's good news. Very good news

You came to the right place Mark

So I thought l'd give you one last example of what we tried to do. So another idea I had once when I was watching a TV show on how they made microchips in the computer industry was why can't we create drug delivery systems like this. So I worked with my graduate student John Santini and Mike Cima who is my collaborator. This is a picture of a chip that has 34 wells on the top and 34 on the bottom (Slide 5). This is a short flat chip. But they can be made to any size and shape and just to illustrate how they work, we use a well in the chip. It's covered in this case with gold. But it stays like this for years. But you can apply one volt by remote control and what you'll see in a matter of seconds is when you apply the voltage the cover comes off and whatever is underneath it can come out. So you could put different amounts of drugs in different wells. This is from another Nature paper we wrote and you

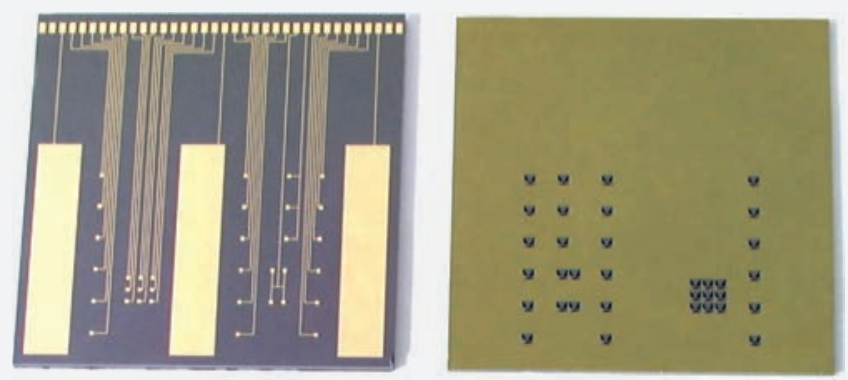

Slide 5

\section{Single compound release}

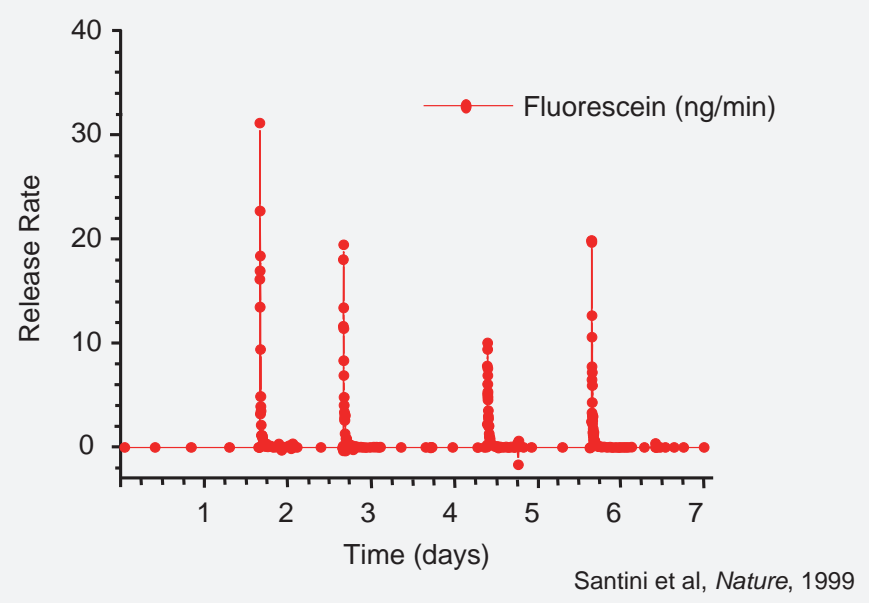

Slide 6

see the drug coming out (Slide 6). Or you could literally like have a pharmacy on a chip where you could have multiple drugs and they could be programmed to come out at any time. We actually have put these into humans. This is going to sound like space age medicine but we actually did it. We worked with a group in Denmark and you can put the chips in the body and communicate with them over a special radio frequency called 
the Medical Implant Communications Service Band and it's approved by various regulatory authorities and then you have this bi-directional communications link that could actually be a cell phone.

The trial we did involved eight patients. We wanted to pick a really difficult drug because people said this wouldn't work because you would get fibrous encapsulation around the chip and large molecules couldn't come out of the chip. So we picked parathyroid hormone, a fairly large peptide. We also chose it because we felt we could make a significant clinical impact because $77 \%$ of the women who take this drug (for osteoporosis), don't keep doing it. To implant the chip, there is a small procedure done in the doctor's office. We got the same pharmacokinetics with less variability than injections and the three key measures of treating osteoporosis were the same as with daily injections. It's actually a little system. There is a chip, a power source, microelectronics, a computer program built into it, and an antennae imprinted on it. That's how you communicate with it. We do get some fibrous encapsulation but not enough to block anything from coming out, and it's about one-fortieth what a pacemaker gets and no inflammatory cells are seen by histology. We're now taking this into a number of directions.

The first direction is making a longer lasting device. The second direction is a personalized birth control system where a woman could turn it on or off anytime. The third area involves a collaboration with Ann Graybiel, a famous neuroscientist at MIT, and Mike Cima to create a new device to modulate pathological neural activity and create devices for treating traumatic brain injury. Such devices will hopefully be able to record and even stimulate neural activity and simultaneously deliver multiple drugs into whatever area they are implanted. A final long term goal involves putting sensors in these chips and then perhaps have the chips deliver a molecule in response to a molecular signal. Thank you very much for having me speak today. It has been an honor to speak to you. 